<smiles>CC(C)CCCC(C)C1CCC2C3CCCC(C)C3CCC12</smiles>

I
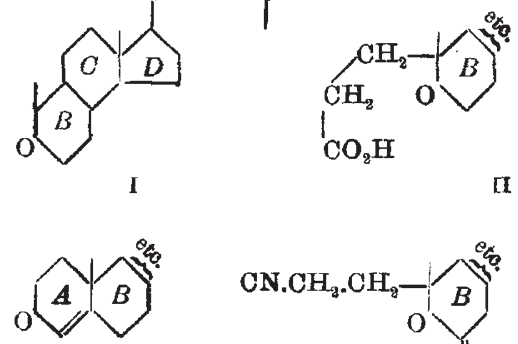

III

although it gave good results with cis-1-methyl-2decalone $^{2}$. The cause is the trans- junction of rings $B$ and $C$, and a similar difficulty was encountered with trans-1-methyl-2-decalone. This obstacle was surmounted by protecting the methylene group adjacent to carbonyl, when the sluggish process can be forced by more vigorous conditions. Our first objective was, however, the Windaus acid (II), because this has already been converted into cholestenone ${ }^{3}$ and hence into cholesterol (Ruzicka, Birch, Dauben).

The hydroxymethylene derivative of the Inhoffen ketone was condensed with methylaniline ${ }^{4}$ and the product with acrylonitrile in the presence of 'Triton B' to give IV. After hydrolysis with acid and later with alkali, the authentic Windaus acid (II) could be separated and purified. The identity with the acid from cholestenone was confirmed by undepressed mixed meiting point and by comparison of rotatory power and X-ray diffraction patterns of the crystals. Mrs. D. Crowfoot Hodgkin kindly carried out the latter experiments and reports that the two specimens submitted to her are identical.

Thus the Inhoffen ketone is a substance that can $b_{e}$ transformed into cholesterol. We now intend to dehydrogenate ring $B$ of this ketone and to attempt a junction with the $B C D$ tricyclic ketones already synthesized in this Laboratory ${ }^{5}$.

A. R. Pinder

R. ROBINSON

Dyson Perrins Laboratory,

University, Oxford. Jan. 23.

${ }^{2}$ Inhoffen and Huang-Minlon, Ber., 72, 1686 (1939).

- Robiuson and Weygand, J. Chem. Soc., 391 (1941).

s Turner, J. Amer. Chem. Soc., 72, 588 (1950).

- Birch and Robinson, J. Chem. Soc., 501 (1944).

'Martin and Robinson, J. Chem. Soc., 491 (1943); 1866 (1949).

\title{
Occurrence of Asperuloside in Daphniphyllum macropodum (Euphorbiacex) and a closely related Glucoside in Monotropa hypopitys Walt. (Pyrolaceæ)
}

As knowledge of the chemical constitution of plant products extends, types of substances, and individual substances, which were formerly thought to be characteristic of certain taxonomic divisions of plants, are found to occur in divisions, which, on other grounds, are considered to be unrelated. The glucoside asperuloside, first isolated by Hérissey ${ }^{1}$, has hitherto been regarded as a characteristic product of plants of the family Rubiacer and has been isolated from many of its species. It will be of interest to the student of chemical taxonomy that, in the course of a study of asperuloside, this glucoside has been

isolated from Daphniphyllum macropodum, which is a Chinese plant of uncertain affinity, placed in the family Euphorbiaceæ, and that a very similar glucoside occurs in the uncommon saprophytic plant Monotropa hypopitys Walt., which is placed in the Ericales, family Pyrolaceæ.

$1.8 \mathrm{gm}$. of asperuloside was isolated from $315 \mathrm{gm}$. fresh leaves of $D$. macropodum, kindly supplied by Mr. J. Gilmour, director of the Royal Horticultural Society's Garden. This material has the following constants : m.p. $126^{\circ}-129^{\circ},[\alpha]_{D^{18}-200^{\circ}} ; \mathrm{C}, 50 \cdot 7$ per cent ; H, 5.6 per cent. The constants of an authentic sample of asperuloside prepared from Rubia tinctorum

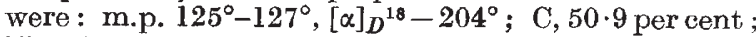
$\mathrm{H}, 5 \cdot 7$ per cent. A mixture of the two preparations melted at $126^{\circ}-129^{\circ}$. The glucoside from Daphni. phyllum crystallized on seeding with the authentic material, and both substances ran at the same rate in two different solvent mixtures on filter-papt $r$ chromatograms.

Asperuloside has a number of highly specific colour reactions which make it very easy to detect. These are also given by a glucoside prepared from Monotropa hypopitys, which is identical with "monotropéine" isolated from this plant by Bridel ${ }^{2}$. The following properties described by Bridel distinguish it from asperuloside ; it is acid to litmus, whereas asperuloside is neutral, decomposes sodium carbonate and has the following constants : m.p. $175^{\circ},[\alpha]_{D}-130 \cdot 4^{\circ}$.

I am indebted to Mr. E. J. H. Corner, of the Botany School, Cambridge, for suggesting the investigation of Daphniphyllum macropodum, and to Dr. R. Hill for his close interest in this work.

Unit of Plant Biochemistry

A. R. TRIM

(Agricultural Research Council),

Biochemical Laboratory,

Cambridge. Nov. 14.

' Hérissey, H., Bull. Soc. Chim. Biol., 7, 1009 (1.925).

${ }^{3}$ Bridel, M., Bull. Soc. Chim. Biol., 5, 722 (1923).

\section{Melting Points of Mixtures of Cetyl Caprate with Lauryl Myristate}

THE work of Oldham and Ubbelohde ${ }^{1}$ suggested that the melting point of mixtures of dipolar compounds may be much lower than predicted by the Le Chatelier - Schröder (or Hildebrand) equation ${ }^{2}$ if one uses components which are able to crystallize in a composite lattice but are sufficiently different in chain-length to lead to the formation of a defective lattice. The formation of lattice flaws is made possible

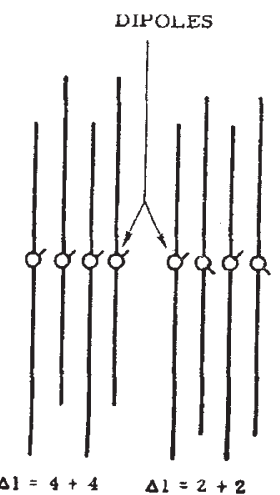

Fig. 1. Alternate possible arrangements of lauryl myristate and cetyl caprate in composite crystal lattices

$\Delta \mathbf{1}=$ size of gaps (in number of $\mathrm{C}$-atoms) in the lattice 